\title{
Non-bleached colonies of massive Porites may attract fishes for selective grazing during mass bleaching events
}

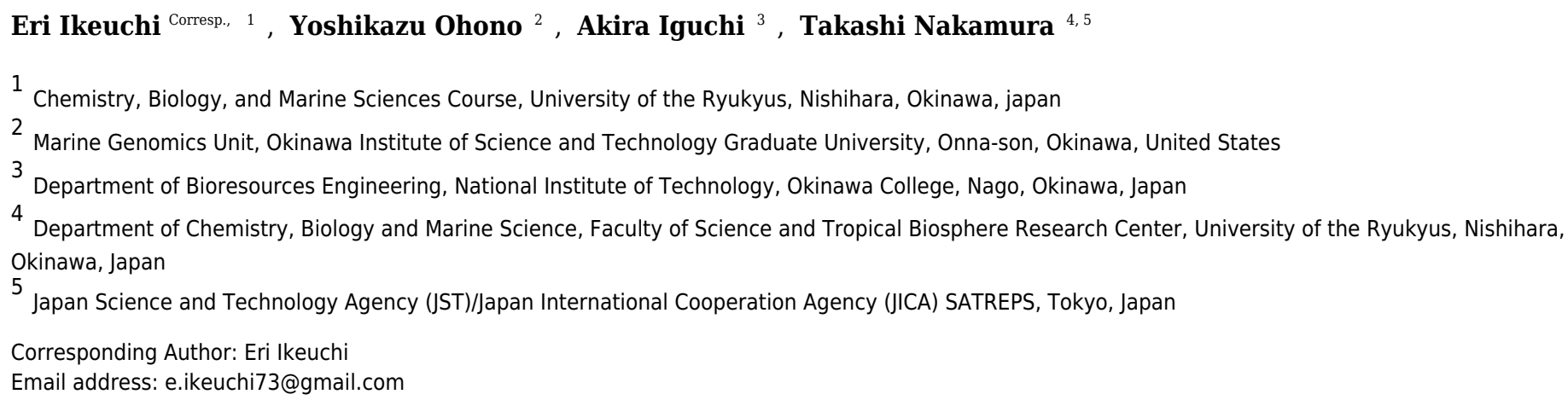

In this study we investigated the variation in grazing scar densities between bleached and non-bleached colonies of massive Porites species in Sekisei Lagoon (Okinawa, southwestern Japan) during a mass bleaching event in 2016. The grazing scar densities and bleaching susceptibility varied among neighboring colonies of massive Porites spp. However, non-bleached colonies had significantly more surface scars than bleached colonies. One explanation for these variations is that corallivorous fishes may selectively graze on non-bleached, thermally tolerant colonies. This is the first report of a relationship between grazing scars and the bleaching status of massive Porites spp. colonies during a mass bleaching event. 


\section{Title}

2 Non-bleached colonies of massive Porites may attract fishes for selective grazing

3 during mass bleaching events

\section{Authors}

6 Eri Ikeuchi ${ }^{1}$, Yoshikazu Ohno ${ }^{2}$, Akira Iguchi $^{3}$, Takashi Nakamura ${ }^{4,5}$

$8{ }^{1}$ Chemistry, Biology, and Marine Sciences Course, Graduate School of Engineering and Science,

9 University of the Ryukyus, Senbaru 1, Nishihara, Okinawa 903-0213, Japan

102 Marine Genomics Unit, Okinawa Institute of Science and Technology Graduate University,

11 1919-1 Tancha, Onna-son, Okinawa 904-0405, Japan

$12{ }^{3}$ Department of Bioresources Engineering, National Institute of Technology, Okinawa College, 13905 Henoko, Nago, Okinawa 905-2192, Japan

$14{ }^{4}$ Department of Chemistry, Biology and Marine Science, Faculty of Science and Tropical 15 Biosphere Research Center, University of the Ryukyus, Senbaru 1, Nishihara, Okinawa 903-0213, 16 Japan

175 Japan Science and Technology Agency (JST)/Japan International Cooperation Agency (JICA)

18 SATREPS, Tokyo, Japan

\section{Communicating Author}

21 Eri Ikeuchi

22 E-mail address: e.ikeuchi73@gmail.com

23 Phone \& Fax No: +81 98-895-8897

\section{Abstract}

26 In this study we investigated the variation in grazing scar densities between bleached and non27 bleached colonies of massive Porites species in Sekisei Lagoon (Okinawa, southwestern Japan) 28 during a mass bleaching event in 2016. The grazing scar densities and bleaching susceptibility 29 varied among neighboring colonies of massive Porites spp. However, non-bleached colonies had 30 significantly more surface scars than bleached colonies. One explanation for these variations is

31 that corallivorous fishes may selectively graze on non-bleached, thermally tolerant colonies. This 32 is the first report of a relationship between grazing scars and the bleaching status of massive Porites 
33 spp. colonies during a mass bleaching event.

\section{Introduction}

Reef fishes belonging to the families Chaetodontidae, Labridae (Bonaldo and Bellwood 2011), and Tetraodontidae (Jayewardene et al. 2009) make scars on the skeletons of corals when they graze on algae, epifauna and endofauna. It is suggested that grazing by parrotfishes in the Caribbean and on the Great Barrier Reef may have serious consequences for the dynamics of coral populations (Bruckner and Bruckner 1998; Mumby 2009; Bonaldo and Bellwood 2011; Bonaldo et al. 2011, 2012, 2014; Cole et al. 2011). As the main target coral species for fish grazing, massive Porites species are the representative corals.

Six massive Porites species are known from marine waters of southwestern Japan (Nishihira and Veron 1995). Many poritid species that have a massive colony morphology are known for their stress tolerance (Loya et al. 2001) and longevity, which may enable them to form relatively large colonies (several meters in diameter) compared with other coral species (Veron 2000). Therefore, massive Porites species are thought to be ecologically important reef builders (Iguchi et al. 2014), and are often used for estimating past environmental conditions, including temperature (e.g., Gagan et al. 2000).

In shallow coral reef habitats around Okinawa Island (southwestern Japan), feeding scars are commonly observed on the surface of massive Porites colonies (Fig. 1). The scar densities vary among neighboring colonies, but the reasons for this variability have not been explored. Direct damage to live tissues caused by grazing can lead to serious problems for corals, as heavily damaged colonies die (e.g., Treeck and Schuhmacher 1997), and this process contributes to the dynamics of coral populations. Furthermore, scars on massive Porites colonies may provide suitable settlement sites for macro-borers including vermetid gastropods (Dendropoma maximum) and Christmas tree worms (e.g., Spirobranchus giganteus) (Nishihira 1996). Therefore, clarifying why grazing scar density variations occur on the surface of Porites spp. is important in determining

61 the ecological processes affecting populations of these corals, and for understanding the 62 establishment and maintenance of microscale biodiversity around Porites colonies.

64 Coral bleaching is one of the threats for degradation of coral reef ecosystems and caused mainly 
65 by thermal stress, followed by the breakdown of the symbiotic relationship between a coral and its 66 symbiotic zooxanthellae (Hoegh-Guldberg 1999). However, sympatric colonies often show 67 variability in bleaching susceptibility (e.g., Jones et al. 2008), which is partially explained by 68 differences in the types of zooxanthellae in the host tissues, particularly differences in stress 69 tolerance between zooxanthellae of clades C and D (e.g., Baker 2003). During summer in 2016, 70 mass coral bleaching occurred in Sekisei Lagoon (southwestern Japan); it involved $>95 \%$ of colonies, which bleached as a consequence of prolonged high seawater temperatures. It is reported that seawater temperatures in Sekisei Lagoon between June and September 2016 were over $30^{\circ} \mathrm{C}$ (Ministry of Environment, 2017). Among many bleached corals at 11 surveyed sites within an area of $<100 \mathrm{~m}$ radius in the lagoon, we observed numerous bleached and non-bleached massive Porites colonies. At these sites we conducted scar density surveys of massive Porites species to investigate the influence of bleaching on fish grazing on these corals.

\section{Materials and Methods}

We selected 11 sites for the survey of massive Porites species (mainly Porites australiensis, $P$. lobata, and P. lutea) in Sekisei Lagoon (Fig. 2 and Table 1). The survey was carried out during 312 September 2016. Prior to taking place, the survey was approved by the Ministry of the Environment.

Underwater observations were conducted at each site using SCUBA. We recorded the following parameters for all massive Porites colonies found during a 30 min diving survey at each site: (i) the degree of scarring ( 5 stages: $0-4$; see Fig. 3 for details); (ii) the maximum colony diameter as a measure of colony size, recorded in one of 5 categories $(1:<30 \mathrm{~cm} ; 2: 31-50 \mathrm{~cm} ; 3: 51-80 \mathrm{~cm}$; 4: 81-110 cm; 5: > $111 \mathrm{~cm}$ ); (iii) depth (m); and (iv) the occurrence of bleaching (bleached vs. non-bleached). In our preliminary survey, we calculated the degree of scarring as the area of grazing scars per that of the colony surface (supplementary table 1). Based on the criteria, we judged the degree of scarring by visual inspection. We defined completely bleached colony not covered by algae as bleached one in this study. Thus, the colonies which we observed seemed to be alive because the dead colonies are soon covered by algae. We removed partially bleached colonies from our analysis. The grazing scars were clearly visible in the field, even on bleached colonies (Fig. 3e and 3f). For several grazed colonies we took high-magnification images of the 
97 images of all Porites colonies using a digital camera (TG-3; OLYMPUS, Japan) in an underwater 98 housing (PT-056; OLYMPUS).

100 To investigate the occurrence of significant relationships among colony size, degree of scarring, 101 and the depth of bleached and non-bleached colonies, we applied the Mann-Whitney U-test using 102 software R ver. 3.2.4 (R Core Team 2016). We used an ordered logistic regression model (a 103 cumulative link mixed model) in which the response variable was the degree of scarring, and the 104 explanatory variables were colony size, depth, bleaching occurrence, and site. This analysis was 105 also performed using software R ver. 3.2.4 (R Core Team 2016) and ordinal package (Christensen 106 2015).

107

\section{Results and Discussion}

109 The results of field surveys of massive Porites species at the 11 sites within Sekisei Lagoon showed 110 that $37 \%$ of the surveyed colonies were bleached (total number of observed colonies: 266; Table 111 1). The percentages of each degree of colony size are as follows; $1: 15.1 \% ; 2: 54.1 \% ; 3: 20.8 \% ; 4$ :

$1127.5 \%$; 5: 2.5\%. Both bleached and non-bleached colonies were recorded at all sites (Fig. 4), but 113 the number of grazing scars on non-bleached colonies was 2.88 times greater than that on bleached 114 colonies (Fig. 5a; Mann-Whitney test, $\mathrm{p}<0.01$ ). We found no significant effect of colony size or 115 habitat depth on the occurrence of bleaching (Fig. 5b and 5c; Mann-Whitney test, p >0.1). The 116 ordered logistic regression model analysis showed that the occurrence of bleaching was the 117 explanatory variable that was significantly correlated with the degree of scarring (Z-score $=-7.406$; $118 \mathrm{p}<0.01)$. In the case of site, no.7 was also marginally significant $(Z$-score $=2.177, \mathrm{p}=0.03)$ but 119 other sites not. Colony size and depth were not significant explanatory variables $(Z$-scores $=-0.268$ 120 and -0.864 , respectively; both $\mathrm{p}$ values $>0.1$ ).

121

122 Although we did not identify the cause of these variations, this is the first report suggesting a 123 relationship between bleaching occurrence and grazing scar densities on massive colonies of 124 Porites spp. during the period of a mass bleaching event. There are several possible explanations 125 for the large variations in grazing scar densities on massive Porites colonies in the field. Firstly, 126 corallivorous fishes may selectively choose colonies based on nutrition. For example, it is thought 127 that the grazing scars caused by parrotfishes occur as they feed on coral tissues, but also on macro128 borers (Rotjan and Lewis 2015), from which they obtain additional nutrients not readily provided 
129 by herbivory. Thus, corallivorous fishes may select non-bleached colonies to obtain certain

130 nutrients in addition to the energy derived from coral tissues (Rotjan and Lewis 2009).

132 Furthermore, corallivorous fishes may selectively prey on coral colonies having thicker tissues, 133 that may be originally tolerant to thermal stress (Loya et al. 2001), as potentially nutritious food 134 sources. Lough and Barnes (2000) reported that the tissue thickness of massive Porites colonies 135 varied among colonies and sites on the Great Barrier Reef. Reproductive stage of the coral may 136 also attract grazer fishes. Rotjan and Lewis (2009) suggested that parrotfishes may selectively prey 137 on the tissue of colonies of Montastrea annuralis containing mature eggs, because of its higher 138 nutritional value. As massive Porites species are dioecious (Harriott, 1983), the scar densities may 139 be variable among male and female colonies. Further studies are required to assess whether 140 differences in coral tissue thickness can be detected by coral predators.

142 The various scar densities among colonies could be produced by random grazing of fishes. As the 143 growth rates of massive Porites vary among colonies (Iguchi et al. 2012; Hayashi et al. 2013), the 144 speed of healing of grazing scars on the colony surface is also likely to be highly variable among 145 colonies. Massive Porites species are reported to suspend growth during bleaching events (Suzuki 146 et al. 2003). In fast-growing colonies, the scars may rapidly be covered by newly formed live 147 tissue, and as a result the colonies could appear to have fewer scars. On the other hand, in colonies 148 having slow growth rates the scars may not heal rapidly, and their number on the surface could 149 appear to be greater. In this context, the bleached colonies in Sekisei Lagoon should have had a 150 much greater scar density than non-bleached colonies because of reduced growth (healing) during 151 the bleaching period.

153 The imbalance between grazing frequency and/or intensity as a function of healing speed (colony 154 growth) should determine the appearance of colonies, but the low scar densities observed for 155 bleached colonies in Sekisei Lagoon cannot be explained by variations in the speed of scar healing. 156 Therefore, we inferred that fishes selectively graze on non-bleached massive Porites colonies (or 157 those less likely to be bleached). Future studies should investigate tissue thickness among grazed 158 and non-grazed colonies, and reciprocal transplantation experiments using fragments of highly159 grazed and non-grazed colonies should be performed to study the mechanisms underlying the 160 temporal and spatial variations in scar densities on the surface of massive Porites colonies. 
161

\section{Acknowledgements}

163 We thank Mitsuhiro Ueno and Masahiko Sunagawa for their support during the field survey. We

164 also thank Kana Kojima and Mariyam Shidha Afzal for their assistances in the field, and insightful 165 comments and suggestions.

166

\section{References}

Baker AC (2003) Flexibility and specificity in coral-algal symbiosis: diversity, ecology, and biogeography of Symbiodinium. Annu Rev Ecol Evol Syst 661-689

Bonaldo RM, Bellwood DR (2011) Parrotfish predation on massive Porites on the Great Barrier Reef. Coral Reefs 30:259-269

Bonaldo RM, Krajewski JP, Bellwood DR (2011) Relative impact of parrotfish grazing scars on massive Porites corals at Lizard Island, Great Barrier Reef. Mar Ecol Prog Ser 423:223-233

Bonaldo RM, Welsh JQ, Bellwood DR (2012) Spatial and temporal variation in coral predation by parrotfishes on the GBR: evidence from an inshore reef. Coral Reefs 31:263-272

Bonaldo RM, Hoey AS, Bellwood DR (2014) The ecosystem roles of parrotfishes on tropical reefs. Oceanography and Marine Biology: An Annual Review 52:81-132

Bruckner A, Bruckner R (1998) Rapid-wasting disease: Pathogen or predator? Science 279:2019_ 2025

Christensen RHB (2015) Ordinal — regression models for ordinal data. R package version 20151$21 \mathrm{http}: / /$ www.cranr-project.org/ package=ordinal/

Cole AJ, Lawton RJ, Pratchett MS, Wilson SK (2011) Chronic coral consumption by butterflyfishes. Coral Reefs 30: 85-93

Gagan MK, Ayliffe LK, Beck JW, Cole JE, Druffel ERM, Dunbar RB, Schrag DP (2000) New views of tropical paleoclimates from corals. Quat Sci Rev 19:45-64

Harriott VJ (1983) Reproductive ecology of four scleractinian species at Lizard Island, Great Barrier Reef. Coral Reefs 2:9-18

Hayashi E, Suzuki A, Nakamura T, Iwase A, Ishimura T, Iguchi A, Sakai K, Okai T, Inoue M, Araoka D, Murayama S, Kawahata H (2013). Growth-rate influences on coral climate proxies tested by a multiple colony culture experiment. Earth Planet Sci Lett 362:198-206

191 Hoegh-Guldberg O (1999) Climate change, coral bleaching and the future of the world's coral reefs. Mar Freshw Res 50:839-866 
193 Iguchi A, Kumagai NH, Nakamura T, Suzuki A, Sakai K, Nojiri Y (2014) Responses of

194 calcification of massive and encrusting corals to past, present, and near-future ocean carbon

195 dioxide concentrations. Mar Pollut Bull 89:348-355

196 Iguchi A, Ozaki S, Nakamura T, Inoue M, Tanaka Y, Suzuki A, Kawahata H, Sakai K (2012)

197 Effects of acidified seawater on coral calcification and symbiotic algae on the massive coral 198 Porites australiensis. Mar Environ Res 73:32-36

199 Jayewardene D, Donahue MJ, Birkeland C (2009) Effects of frequent fish predation on corals in 200 Hawaii. Coral Reefs 28:499-506

201 Jones AM, Berkelmans R, van Oppen MJ, Mieog JC, Sinclair W (2008) A community change in the algal endosymbionts of a scleractinian coral following a natural bleaching event: field 203 evidence of acclimatization. Proceedings of the Royal Society of London B: Biological Sciences, 275:1359-1365

Lough JM, Barnes DJ (2000) Environmental controls on growth of the massive coral Porites. J Exp Mar Bio Ecol 245:225-243

207

Loya Y, Sakai K, Yamazato K, Nakano Y, Sambali H, Van Woesik, R (2001) Coral bleaching: the 208 winners and the losers. Ecol Lett 4:122-131

Ministry of the Environment (2017) http://kyushu.env.go.jp/naha/pre_2017/post_28.html 210 (Accessed 16 May 2017) (In Japanese)

211 Mumby PJ (2009) Herbivory versus corallivory: are parrotfish good or bad for Caribbean coral reefs? Coral Reefs 28:683-690

213 Nishihira M (1996) Ecology of footing. Heibonsha, Tokyo (in Japanese)

214 Nishihira M, Veron JEN (1995) Hermatypic corals of Japan. Tokyo: Kaiyusha

215 R Core Team (2016) R: A language and environment for statistical computing. R Foundation for 216 Statistical Computing, Vienna, Austria. Available at https:/www.R-project.org/

217 Rotjan RD, Lewis SM (2005) Selective predation by parrotfishes on the reef coral Porites 218 astreoides. Marine Ecology Progress Series 305:193-201

219 Rotjan RD, Lewis SM (2009) Predators selectively graze reproductive structures in a clonal marine 220 organism. Marine Biology 156:569-577

Suzuki A, Gagan MK, Fabricius K, Isdale PJ, Yukino I, Kawahata H (2003) Skeletal isotope microprofiles of growth perturbations in Porites corals during the 1997-1998 mass bleaching event. Coral Reefs 22:357-369 
225 transplantation technology - options for reef rehabilitation. Mar Ecol Prog Ser 150:287-292

226 Veron JEN (2000) Corals of the world, vol. 3. Townsville: Australian Institute of Marine Science 227 


\section{Figure 1}

Figure 1. Grazing scars on the surface of massive Porites.

(a) The yellow box shows the part of the surface enlarged as the image in (b). Scale bar: 20 $\mathrm{cm}$. (b) Microscopic image of the part of the Porites corresponding to the yellow box in (a). Red dotted lines show the area of the grazing scar. The yellow box area indicates the area enlarged as the image in (c). Scale bar: $5 \mathrm{~mm}$. (c) Marginal area of the edge of the scar in (b). Black arrows indicate light-colored polyps under regeneration. Scale bar: $1 \mathrm{~mm}$.
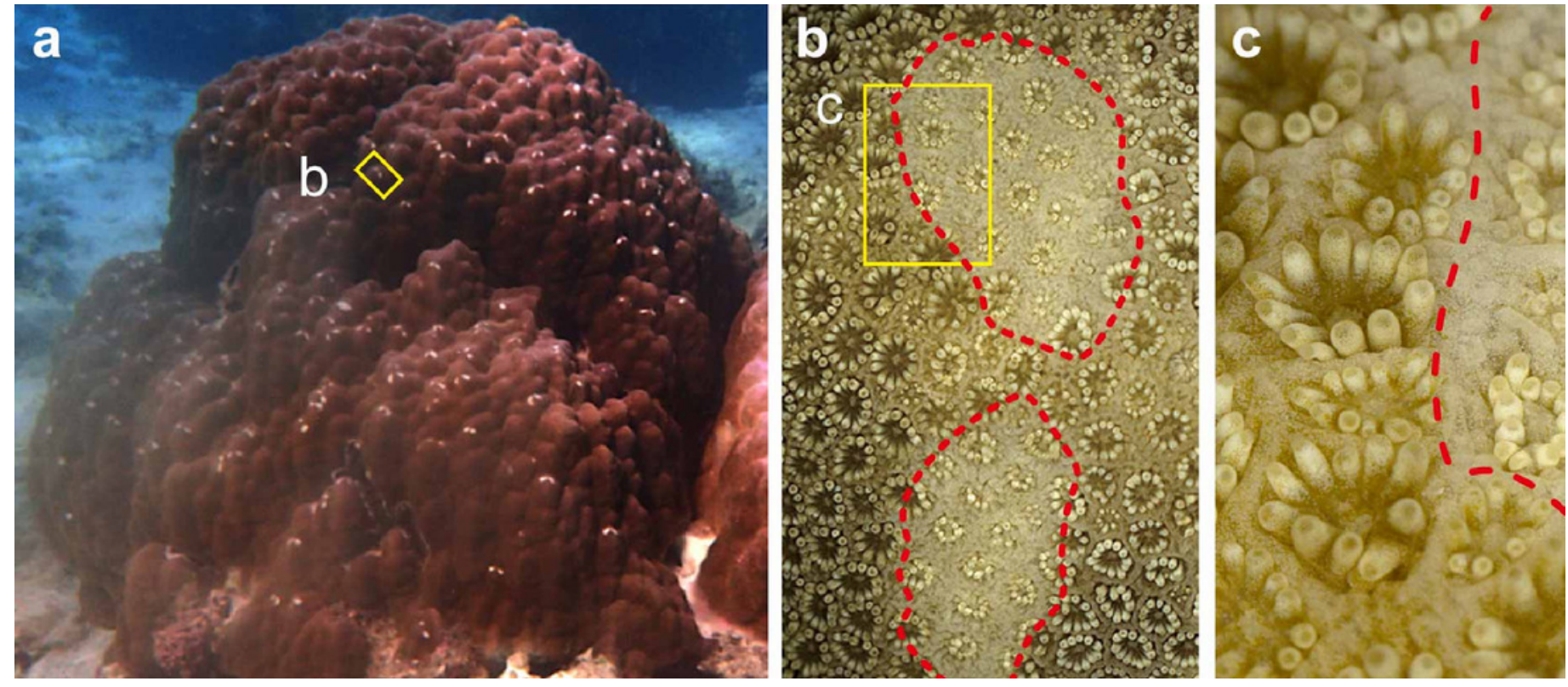


\section{Figure 2}

Figure 2. Location of the study sites within Sekisei Lagoon, Okinawa, Japan.

Map of Sekisei Lagoon and location of 11 survey sites.

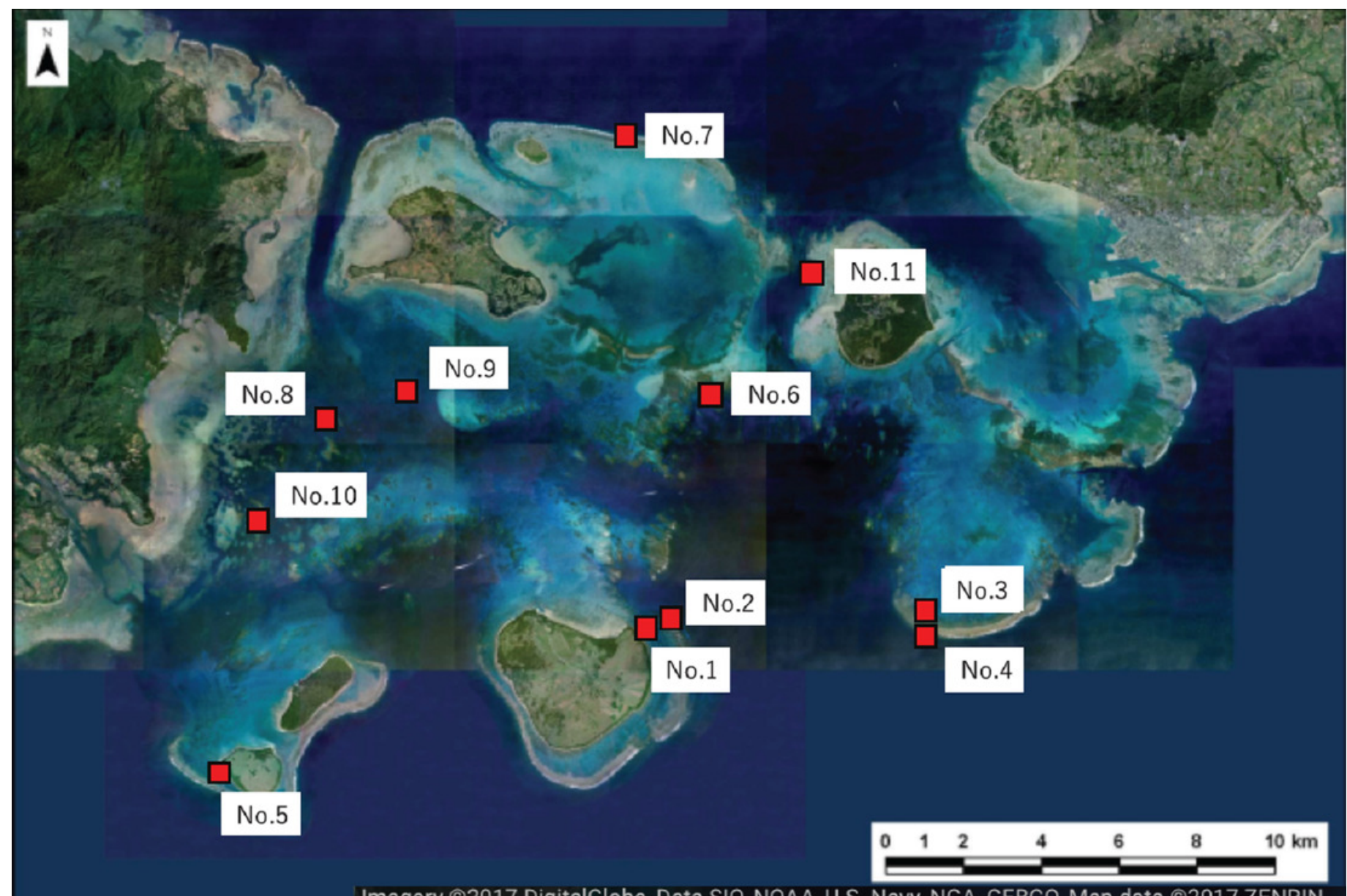




\section{Figure 3}

Figure 3. Images showing the degree of scarring on massive Porites in the field

(a) < 5\%; (b) 6-15\%; (c) 16-25\%; (d) > 26\%; scale bars a-d: $10 \mathrm{~cm}$, e and f: $1 \mathrm{~cm}$. Magnified images of a grazing scar on bleached (e) and non-bleached (f) colonies in the field.
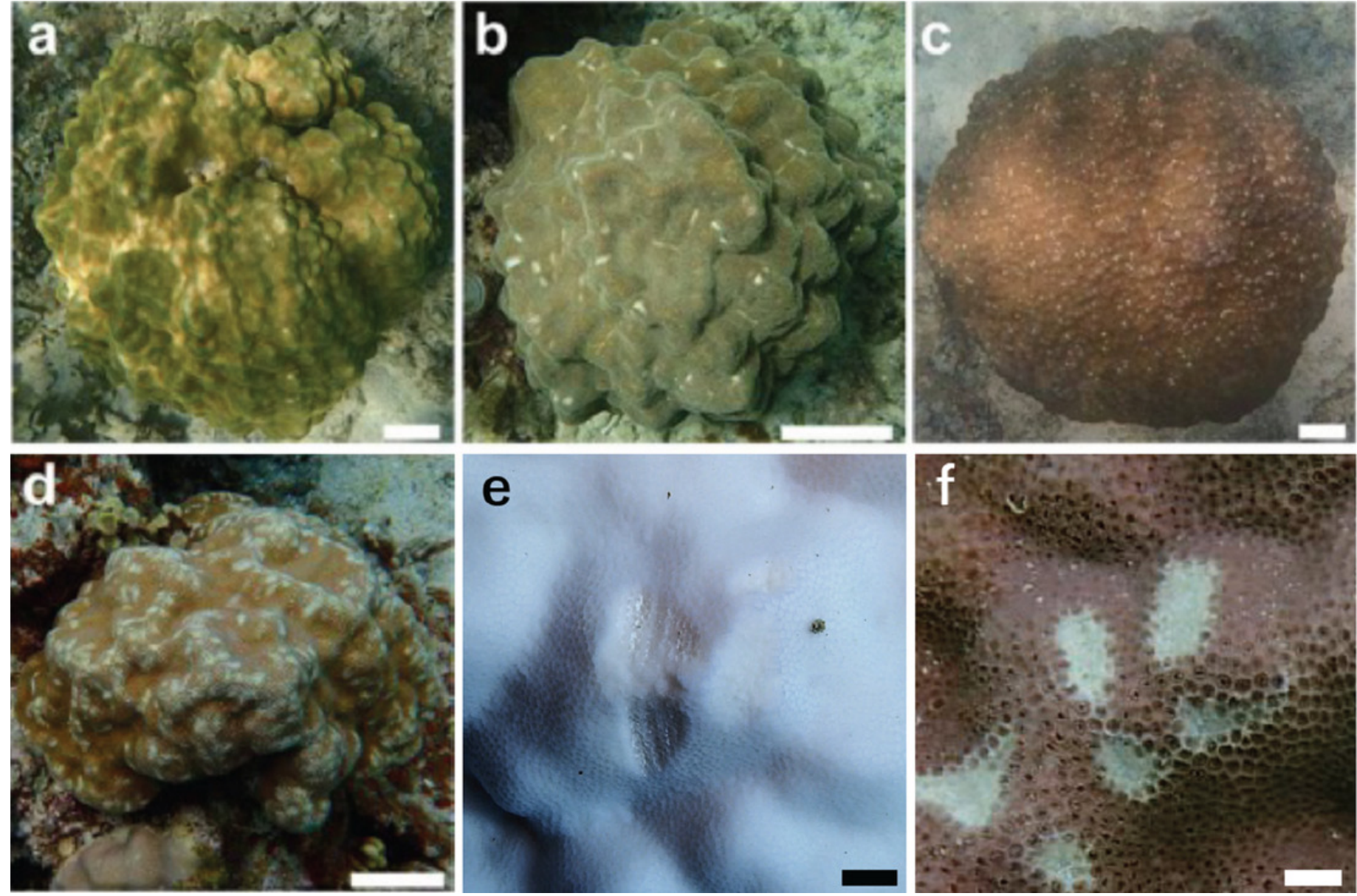
Figure 4

Figure 4. Frequency of bleached and non-bleached colonies of massive Porites recorded at each site.

$X$ axis: site number; $Y$ axis: number of colonies.

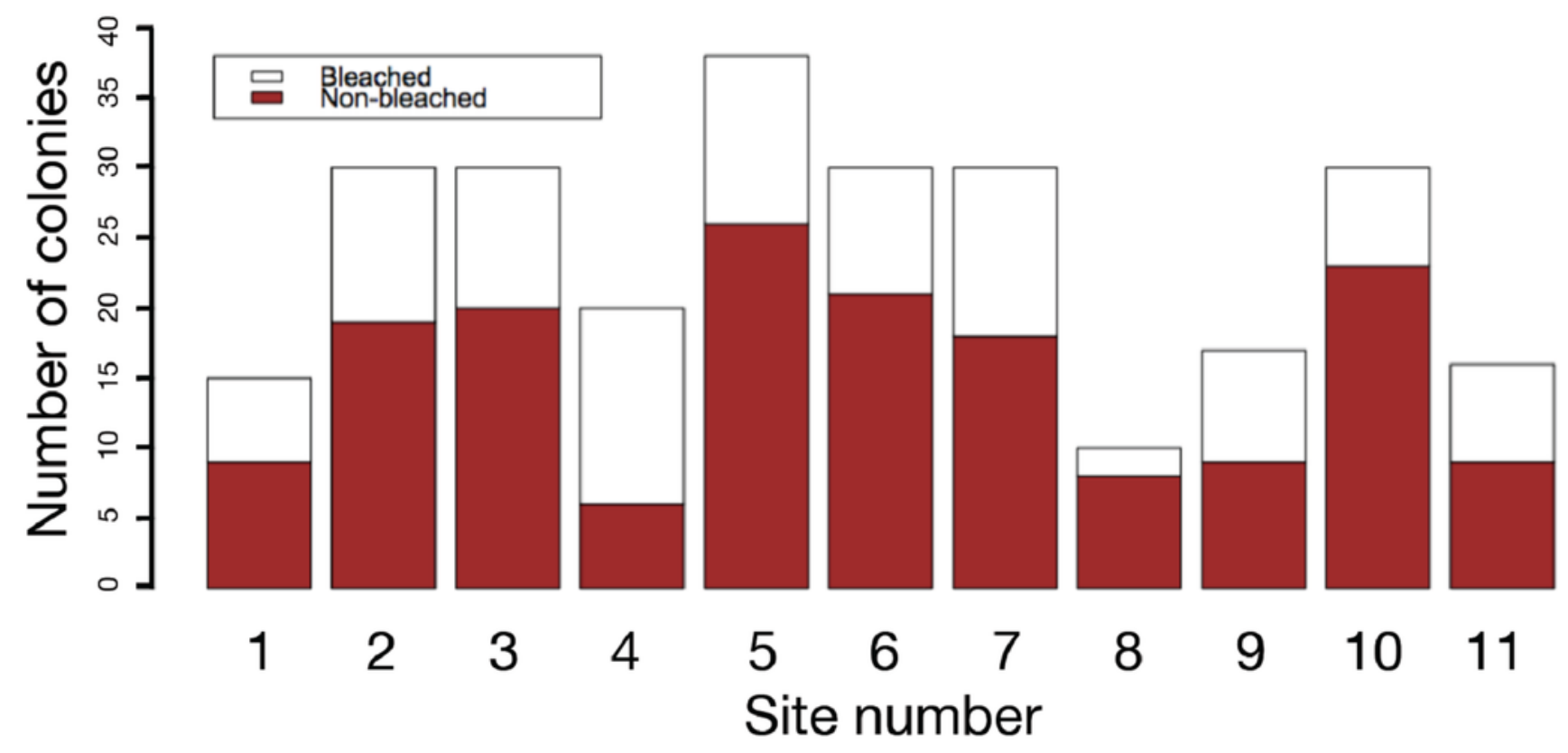


Figure 5

Figure 5. Box plots of each factor between non-bleached and bleached colonies of massive Porites.

Box plots of the degree of scarring (a), size of colonies (b), and depth (c) between nonbleached (NB) and bleached (B) colonies of massive Porites.
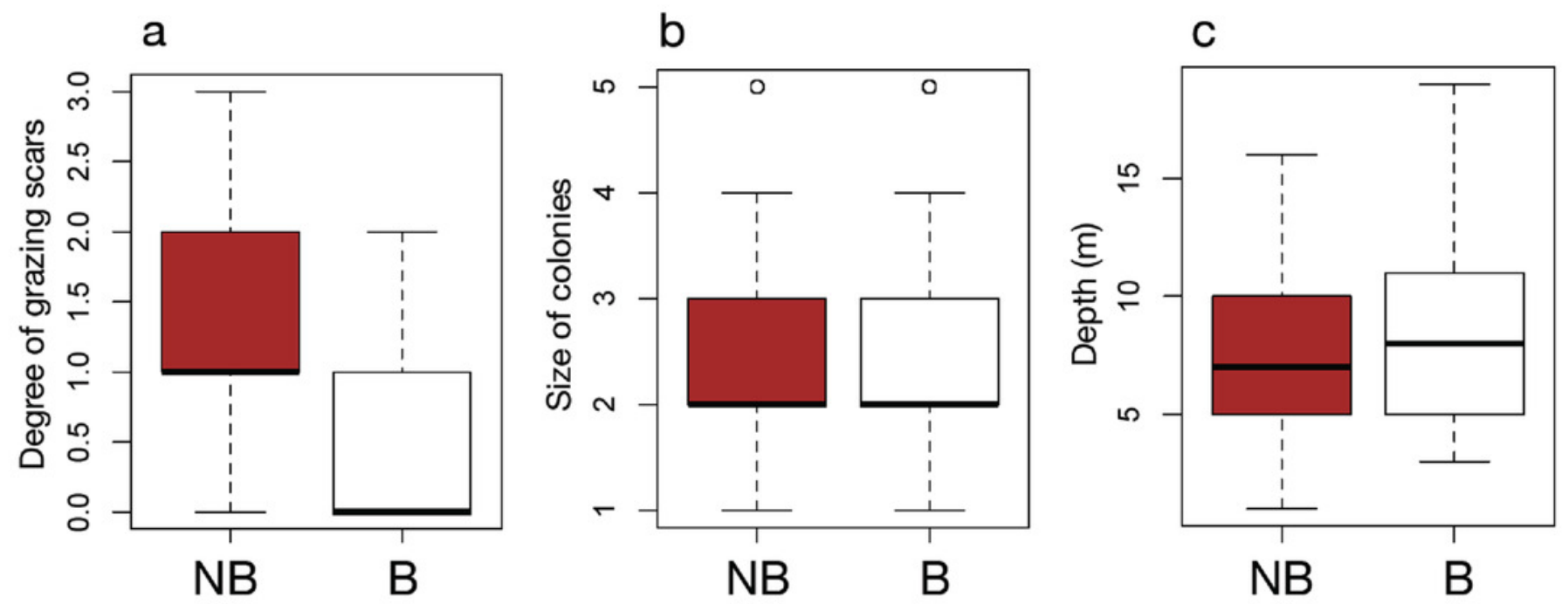


\section{Table $\mathbf{1}$ (on next page)}

Table 1. Details of study sites. 


\begin{tabular}{|c|c|c|c|c|c|c|}
\hline No. & latitude & longitude & depth (m) & $\begin{array}{c}\text { No. of bleached } \\
\text { colonies }\end{array}$ & $\begin{array}{c}\text { No. of non-bleached } \\
\text { colonies }\end{array}$ & $\begin{array}{c}\text { Total no. of } \\
\text { colonies }\end{array}$ \\
\hline 1 & $\mathrm{E} 24^{\circ} 14^{\prime} 54.5^{\prime \prime}$ & $\mathrm{N} 124^{\circ} 01^{\prime} 50.0^{\prime \prime}$ & $7.6 \pm 1.5$ & 6 & 9 & 15 \\
\hline 2 & E2415'01.1" & 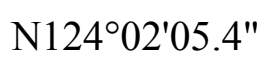 & $6.4 \pm 0.6$ & 11 & 19 & 30 \\
\hline 3 & $\mathrm{E} 24^{\circ} 15^{\prime} 04.1^{\prime \prime}$ & 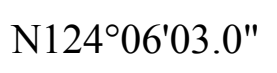 & $4.3 \pm 1.3$ & 10 & 20 & 30 \\
\hline 4 & $\mathrm{E} 24^{\circ} 14^{\prime} 50.8^{\prime \prime}$ & 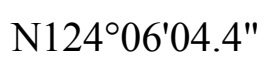 & $13.7 \pm 2.4$ & 14 & 6 & 20 \\
\hline 5 & $\mathrm{E} 24^{\circ} 12^{\prime} 45.5^{\prime \prime}$ & N1235'14.7" & $5.4 \pm 1.5$ & 12 & 26 & 38 \\
\hline 6 & E24ำ18'17.6" & 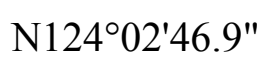 & $8.3 \pm 1.8$ & 9 & 21 & 30 \\
\hline 7 & $\mathrm{E} 24^{\circ} 22^{\prime} 02.5^{\prime \prime}$ & N12401'27.0" & $13.4 \pm 1.4$ & 12 & 18 & 30 \\
\hline 8 & $\mathrm{E} 24^{\circ} 17^{\prime} 55.8^{\prime \prime}$ & N1235'ㄷㄴ & $4.5 \pm 2.4$ & 2 & 8 & 10 \\
\hline 9 & $\mathrm{E} 24^{\circ} 18^{\prime} 18.4^{\prime \prime}$ & 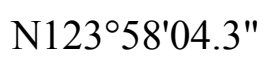 & $7.2 \pm 2.6$ & 8 & 9 & 17 \\
\hline 10 & $\mathrm{E} 24^{\circ} 16^{\prime} 25.5^{\prime \prime}$ & N123ํ5'51.2" & $10.5 \pm 0.5$ & 7 & 23 & 30 \\
\hline 11 & $\mathrm{E} 24^{\circ} 20^{\prime} 00.0^{\prime \prime}$ & N12404'18.3" & $4.3 \pm 0.9$ & 7 & 9 & 16 \\
\hline
\end{tabular}

